\title{
Neuroimaging Biomarkers in SCA2 Gene Carriers
}

\author{
Mario Mascalchi ${ }^{1, *}$ and Alessandra Vella ${ }^{2}$ \\ 1 Department of Clinical and Experimental Biomedical Sciences, University of Florence, 50121 Florence, Italy \\ 2 Nuclear Medicine at University Hospital, 53100 Siena, Italy; a.vella@ao-siena.toscana.it \\ * Correspondence: mario.mascalchi@unifi.it; Tel.: +39-329-808-1701
}

Received: 21 December 2019; Accepted: 31 January 2020; Published: 4 February 2020

\begin{abstract}
A variety of Magnetic Resonance (MR) and nuclear medicine (NM) techniques have been used in symptomatic and presymptomatic SCA2 gene carriers to explore, in vivo, the physiopathological biomarkers of the neurological dysfunctions characterizing the associated progressive disease that presents with a cerebellar syndrome, or less frequently, with a levodopa-responsive parkinsonian syndrome. Morphometry performed on T1-weighted images and diffusion MR imaging enable structural and microstructural evaluation of the brain in presymptomatic and symptomatic SCA2 gene carriers, in whom they show the typical pattern of olivopontocerebellar atrophy observed at neuropathological examination. Proton MR spectroscopy reveals, in the pons and cerebellum of SCA2 gene carriers, a more pronounced degree of abnormal neurochemical profile compared to other spinocerebellar ataxias with decreased NAA/Cr and $\mathrm{Cho} / \mathrm{Cr}$, increased $\mathrm{mi} / \mathrm{Cr}$ ratios, and decreased NAA and increased $\mathrm{mI}$ concentrations. These neurochemical abnormalities are detectable also in presymtomatic gene carriers. Resting state functional MRI (rsfMRI) demonstrates decreased functional connectivity within the cerebellum and of the cerebellum with fronto-parietal cortices and basal ganglia in symptomatic SCA2 subjects. ${ }^{18}$ F-fluorodeoxyglucose Positron Emission Tomography (PET) shows a symmetric decrease of the glucose uptake in the cerebellar cortex, the dentate nucleus, the brainstem and the parahippocampal cortex. Single photon emission tomography and PET using several radiotracers have revealed almost symmetric nigrostriatal dopaminergic dysfunction irrespective of clinical signs of parkinsonism which are already present in presymtomatic gene carriers. Longitudinal small size studies have proven that morphometry and diffusion MR imaging can track neurodegeneration in SCA2, and hence serve as progression biomarkers. So far, such a capability has not been reported for proton MR spectroscopy, rsfMRI and NM techniques. A search for the best surrogate marker for future clinical trials represents the current challenge for the neuroimaging community.
\end{abstract}

Keywords: spinocerebellar ataxia type 2; magnetic resonance; brainstem; cerebellum; nuclear medicine

\section{Introduction}

Spinocerebellar ataxia type 2 (SCA2) (OMIM 183090) is an autosomal dominantly inherited condition due to expansion of an unstable cytosine-adenineguanine (CAG) trinucleotide repeat within the coding sequence of the SCA2 gene located at chromosome 12q24.1 and belongs to the polyglutamine (PolyQ) diseases group [1].

Clinical features of SCA2 include progressive neurological dysfunctions that present with either a cerebellar syndrome or, less frequently, Dopa-responsive Parkinson's syndrome [2] (Table 1). 
Table 1. Signs and Symptoms of Spinocerebellar ataxia type 2.

\begin{tabular}{c}
\hline Common (Adult Phenotype) \\
\hline Progressive cerebellar ataxia \\
Dysarthria \\
Dysphagia \\
Oculomotor dysfunction \\
Pyramidal signs \\
Signs of lower motor neuron degeneration \\
Extra-pyramidal features * \\
Sensory-motor peripheral neuropathy \\
Painful muscle cramps \\
Autonomic dysfunction \\
Olfactory deficit \\
Sleep disturbances \\
Cognitive decline \\
Psychiatric symptoms \\
Uncommon (Infantile Phenotype) \\
Developmental delay \\
Facial dysmorphism \\
Retinitis pigmentosa \\
Myoclonus-epilepsy \\
\hline Early-onset L-dopa-responsive parkinsonism can represent clinical presentation in some families.
\end{tabular}

Gross neuropathological examination in brain of patients with genetically proven SCA2 reveals an olivo pontocerebellar atrophy (OPCA) with extension of the volume loss to the frontal lobes and spinal cord in advanced phases [3,4]. Histological examination demonstrates a distributed pattern of neuronal loss, which is particularly severe in thePurkinje neurons of the cerebellar cortex, gliosis and myelin loss $[4,5]$.

Herein we review data concerning in vivo brain structure and microstructure evaluated with Magnetic Resonance (MR) imaging, neurochemical profiles assessed with proton MR spectroscopy, and functions explored with Blood Oxygenation Level Dependent (BOLD) MR contrast, so called functional MR Imaging (fMRI), and nuclear medicine (NM) techniques, in human carriers of SCA2 gene. To that end we conducted a systematic and comprehensive literature search to select relevant studies published up to September 2019 using the Medline database (Pubmed). The following keywords were selected: "Spinocerebellar ataxia 2", "Spectroscopy spinocerebellar ataxia 2", "Spectroscopy SCA2", "MR spinocerebellar ataxia 2", "MR SCA2", "Functional MR spinocerebellar ataxia 2", "Functional MR SCA2", "SPECT spinocerebellar ataxia 2", "SPECT SCA2", "PET spinocerebellar ataxia 2", and "PET SCA2."

These neuroimaging data can serve as physiopathological, progression and surrogate biomarkers [6,7], whereas the wide availability of the molecular genetic test has considerably reducedthe diagnostic role of neuroimaging biomarkers in SCA2. In view of future therapeutic trials, particular attention will be paid to the studies investigating pre-symptomatic SCA2 carriers who, thanks to the autosomal dominant inheritance of the disease, can easily been recognized by the molecular genetic test in family members of affects patients. The pre-symptomatic subjects are in fact those for whom the major beneficial effects of new therapies for SCA2 are expected.

\section{Structural and Microstructural MR Imaging}

T1 weighted images show in SCA2 patients, the typical brainstem and cerebellar atrophy consistent with an OPCA pattern [7,8] (Figure 1). This is combined in proton density and T2 weighted images with diffuse hyperintensity of the cerebellar white matter, middle cerebellar peduncles and central pons with a characteristic sparing in the latter of the pyramidal tracts and medial lemnisci featuring a 
"cross" sign [9,10] (Figure 1). Differently from multiple system atrophy, the T2 signal in the striata is normal $[9,11]$ (Figure 1).

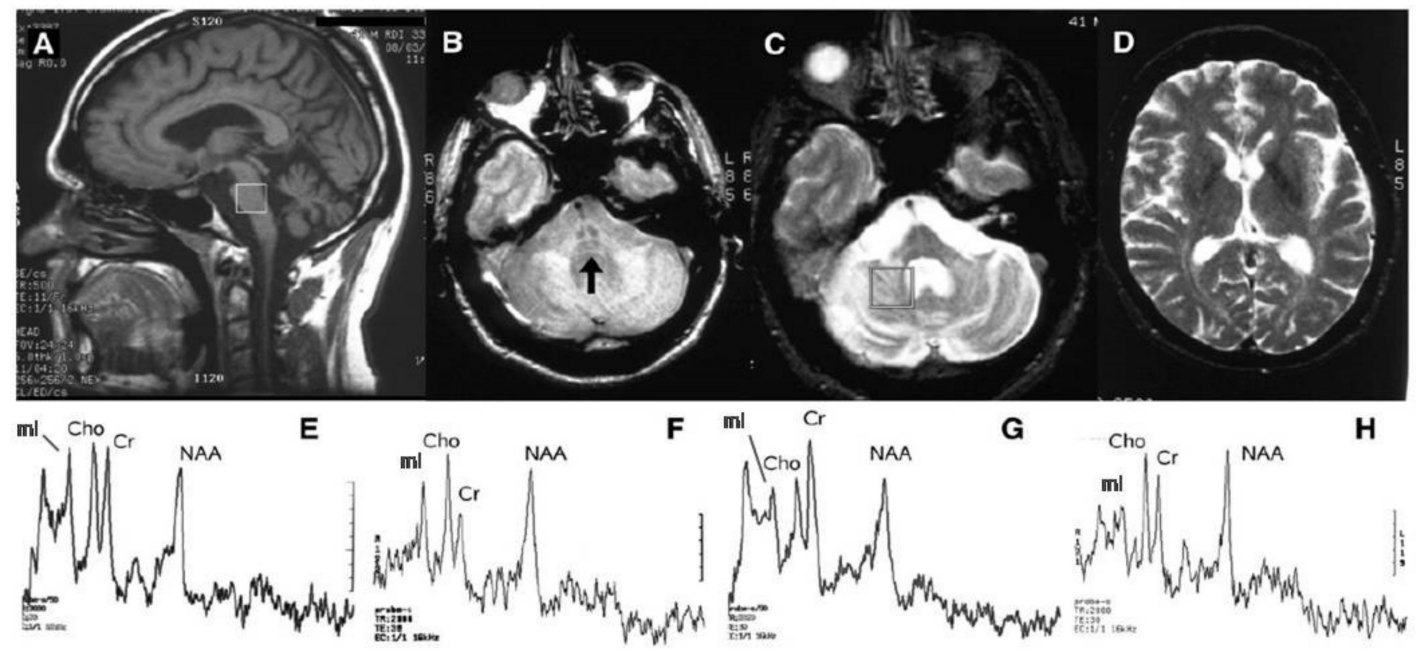

Figure 1. MR imaging and proton MR spectroscopy in a symptomatic 41-year-old man with SCA2. Sagittal T1 weighted (A), axial proton density (B) and T2 weighted (C) images show a pattern consistent with olivopontocerebellar atrophy with evidence of the "cross sign" (arrow) in (B). The T2 signal in the basal ganglia (D) is normal. Proton MR spectroscopy (STEAM TR $2000 \mathrm{~ms}$ TE $30 \mathrm{~ms}$ ) of $8 \mathrm{~mL}$ single voxels placed in the basis pontis (white square in A) of the SCA2 patient (E) and of a healthy control (F), and in the deep right cerebellar hemisphere (white square in C) of the SCA2 patient (G) and of the healthy control $(\mathrm{H})$, show lower $\mathrm{NAA} / \mathrm{Cr}, \mathrm{Cho} / \mathrm{Cr}$ and $\mathrm{NAA} / \mathrm{mI}$ ratios in the SCA2 patient in both locations. Modified and reproduced with permission fromMascalchi M. and Vella A.: Magnetic resonance and nuclear medicine imaging in ataxias.Handb Clin Neurol 103: 85-110, 2012.

Morphometry performed on T1-weighted images using volumetry of regions of interest or whole-brain analytical software, including voxel-based morphometry (VBM) or tensor-based morphometry, allows a quantitative assessment of the selective brainstem and cerebellar atrophy in SCA2 [12-14] (Figure 2) which is already present in pre-symptomatic gene carriers $[15,16]$ (Figure 3).Atrophy of the right temporo-occipital cortex (parahippocampal, fusiform and lingual gyri) was observed in a meta-analysis of the VBM studies [14] (Figure 2).Striata and thalami have normal volumes $[12,14]$.

Volumes of the brainstem and cerebellum showed inverse correlations with severity of clinical deficit [17], age of onset and CAG repeat length [16].

Analysis of fractal dimension has revealed that structural complexities of the cerebral and cerebellar cortex and white matter are decreased [18].

Diffusion MR imaging, using regions of interest, histogram analyses or tractography or tract-based spatial statistics, allows one to quantitatively measure the symmetric distributed microstructural damage of the T2 hyperintense or normal white matter in the brainstem, cerebellar peduncles, cerebellum and corticospinal tracts of SCA2 gene carriers [9,17,19-23] (Figure 4). Additional areas of increased diffusivity and decreased fractional anisotropy can be observed in the thalamus, corpus callosum and cerebral hemispheric white matter $[17,20,21,23]$.

Generally, modifications of diffusion properties in the brain of SCA2 gene carriers correlated with ataxia severity $[9,17,20,21]$, cognitive scores [22] and disease duration [17]. 


\section{Panel A}

\section{Panel B}

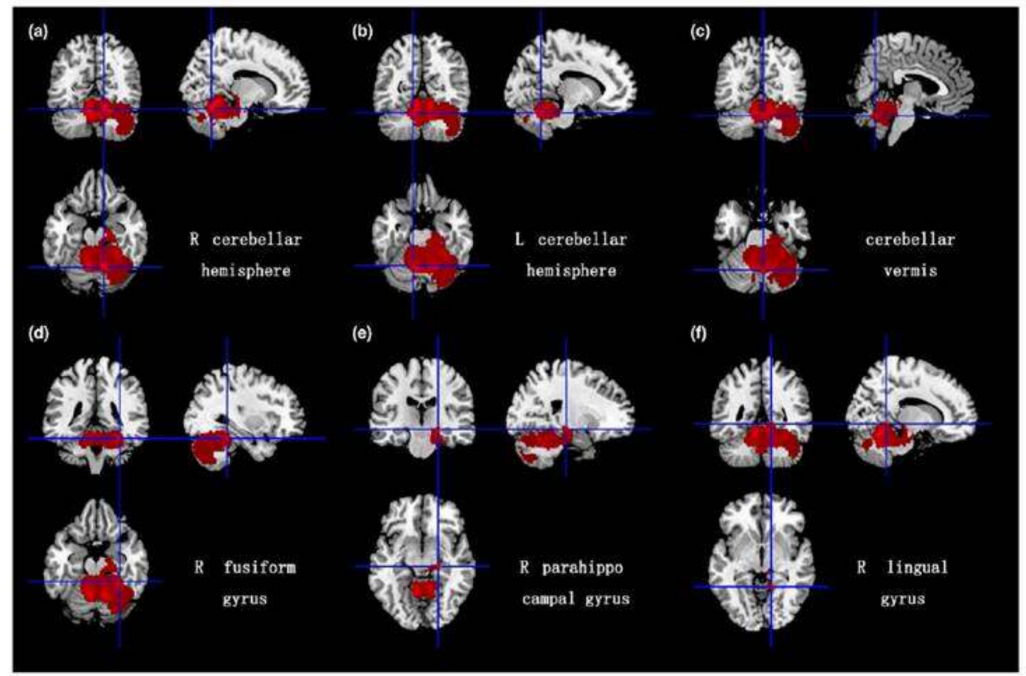

\section{(a)}

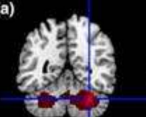

antors

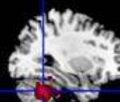

(b)
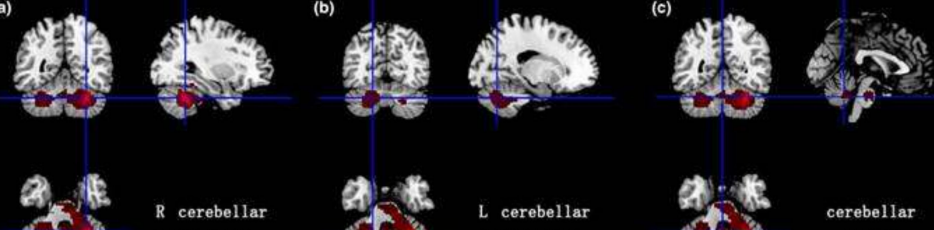

R cerebellar
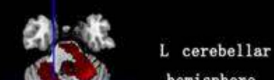

hemi sphere

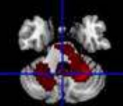

cerebellar hemisphere

(e)

(a)
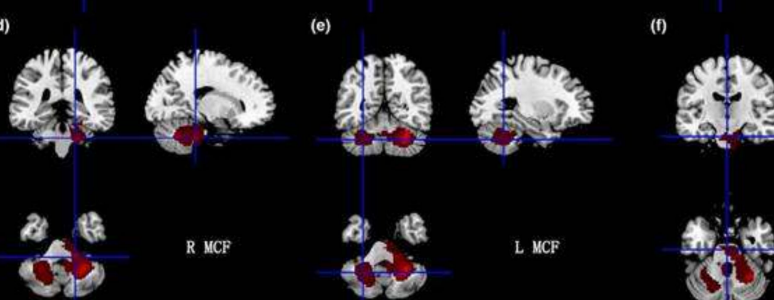

(5)

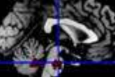

R MCF

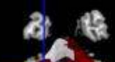

L. MCF

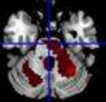

Pons

(h)

(g)
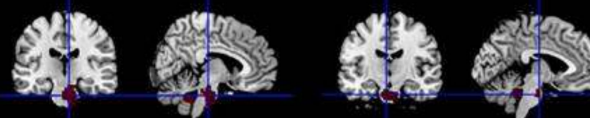

4.)

R cortico-spinal projections

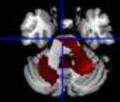

L cortico-spinal projections

Figure 2. (A,B).Results of a meta-analysis of 5 VBM studies in 65 SCA2 gene carriers and 124 healthy controls. Panel A shows atrophy (in red) of the gray matter in bilateral cerebellar hemispheres, cerebellar vermis, the right fusiform gyrus, right parahippocampal gyrus and the right lingual gyrus. Panel B shows the atrophy (in red) of the white matter in bilateral cerebellar hemispheres, cerebellar vermis, middle cerebellar peduncles, pons and bilateral cortico-spinal projections. Reproduced from Han Q, Yang J, Xiong H and Shang H: Voxel-based meta-analysis of gray and white matter volume abnormalities in spinocerebellar ataxia type 2. Brain Behavior 8: e01099, 2018. 

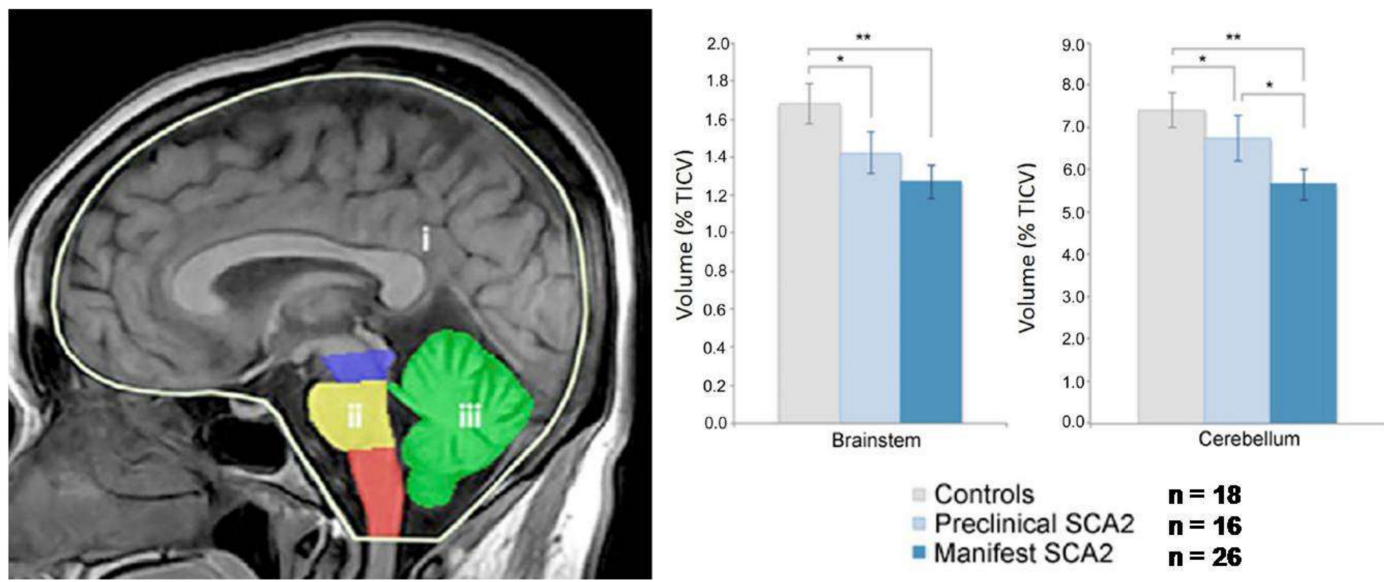

Figure 3. Volumetry in preclinical and manifest SCA2 gene carriers. The volumes of the brainstem (ii) comprising the mesencephalon (blue), pons (yellow) and medulla oblongata (orange), and the cerebellum (iii) (green), both normalized to the total intracranial volume (TICV) (i) (left panel), are significantly $\left(^{* *}=p<0.0001\right.$ and $\left.{ }^{*}=p<0.05\right)$ lower in manifest and preclinical SCA2 gene carriers than in controls (right panel). Modified fromReetz K., Rodríguez-Labrada R., Dogan I, Mirzazade S., Romanzetti S., Schulz J.B., Cruz-Rivas E.M., Alvarez-Cuesta J.A., Aguilera Rodríguez R., Gonzalez Zaldivar Y., et al.: Brain atrophy measures in preclinical and manifest spinocerebellar ataxia type 2. Ann Clin Transl Neurol 5:128-137, 2018.

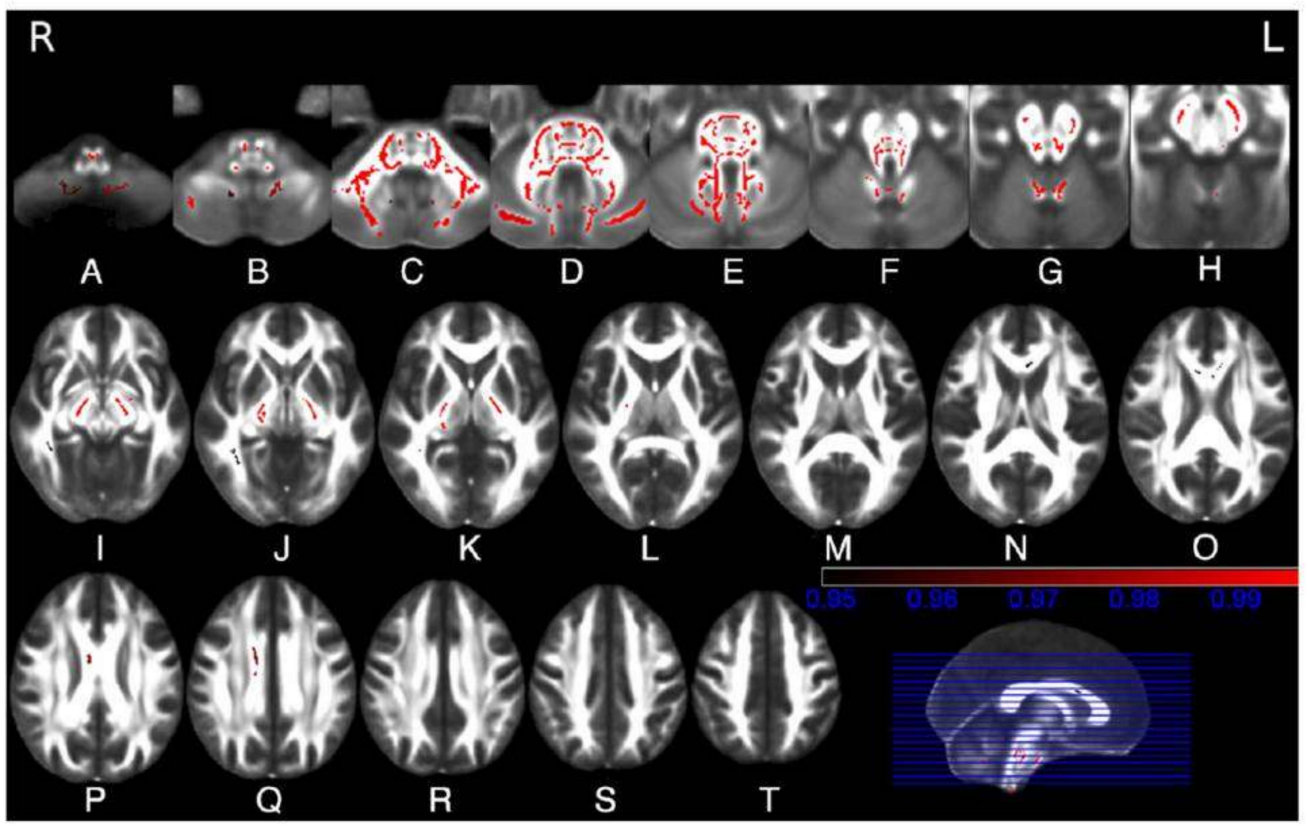

Figure 4. (A-T). Tract-basedspatial statistical analysis of diffusion tensor imaging data in 10 SCA2 patients vs. 10 healthy controls. Maps show in red the clusters of significantly reduced fractional anisotropy in white matter tracts in the SCA2 patients. These include the inferior $(\mathbf{B}, \mathbf{C})$, middle $(\mathbf{C}, \mathbf{D})$ and superior $(\mathbf{E}, \mathbf{F})$ cerebellar peduncle, the cerebellar white matter $(\mathbf{C}, \mathbf{D}, \mathbf{E}, \mathbf{F})$, the medial and lateral lemnisci and the spinothalamic tracts $(\mathbf{D}, \mathbf{E}, \mathbf{F})$, the transverse pontine fibres $(\mathbf{D}, \mathbf{E})$, the corticospinal tracts at the level of the internal capsule $(\mathbf{J}, \mathbf{K}, \mathbf{L})$, cerebral peduncles $(\mathbf{G}, \mathbf{H}, \mathbf{I})$, basis pontis $(\mathbf{C}, \mathbf{D})$ and bulbar pyramis $(\mathbf{A}, \mathbf{B})$, the corpus callosum $(\mathbf{N}, \mathbf{O}, \mathbf{P}, \mathbf{Q})$, the right inferior longitudinal fasciculus $(\mathbf{I}, \mathbf{J})$ and the inferior fronto-occipital fasciculus $(\mathbf{I}, \mathbf{J})$. Reproduced with permission from Della Nave R., Ginestroni A., Tessa C., Salvatore E., De Grandis D, Plasmati R, Salvi F, De Michele G, Dotti MT, Piacentini S, et al.: Brain white matter damage in SCA1 and SCA2. An in vivo study using voxel-based morphometry, histogram analysis of mean diffusivity and tract-based spatial statistics. NeuroImage 43: 10-19, 2008. 
Morphometry $[13,23]$ (Figure 5) and diffusion MR $[23,24]$ in small size longitudinal studies documented progression of neurodegeneration in terms of accelerated volume loss and microstructural changes in SCA2 compared to age matched healthy control subjects. This proves their capability to serve as progression biomarkers. Notably, a greater sensitivity (effect size) of morphometry than clinical scores was reported in one study [23].

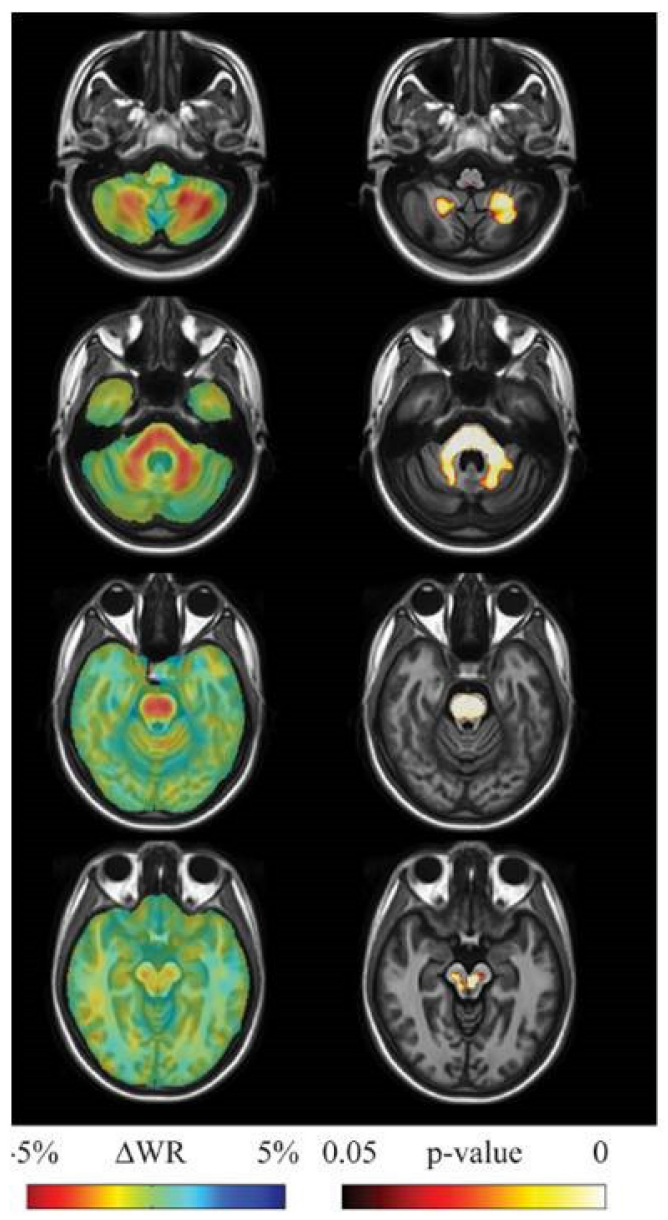

Figure 5. Results of longitudinal between group (10 SCA2 vs. 16 healthy controls, each examined with a mean interval of 3.3 years between initial and follow-up MRI) tensor-based morphometry analysis. Left panel: sample of axial views of the difference in average longitudinal warp rate (WR) maps between SCA2 patients and healthy controls, where red indicates local thinning and blue indicates local enlargement. Right panel: voxel-wise threshold-free cluster enhancement corrected $p$-value maps at the same levels, testing the null hypothesis of zero differences in WR between SCA2 patients and healthy controls. Highlighted clusters indicate significantly $(p<0.05)$ accelerated volume loss in SCA2 patients when compared to healthy controls. SCA2 patients exhibit significantly accelerated volume loss in the midbrain (substantia nigra and medial lemniscus, bilaterally, right lateral lemniscus and central region corresponding to decussation of the superior cerebellar peduncles), the entire basis pontis, the middle cerebellar peduncles and posterior medulla corresponding to the gracilis and cuneatus tracts and nuclei. The cerebellum shows accelerated loss of the white matter in the hemispheric and peridentate regions and of the gray matter in the cerebellar cortex of the inferior portions of the cerebellar hemisphers. Reproduced from Mascalchi M, Diciotti S, Giannelli M, Ginestroni A, Soricelli A, Nicolai E, Aiello M, Tessa C, Galli L, Dotti MT, et al.: Progression of brain atrophy in SCA2. A longitudinal TBM study.PLoS One25; 9(2):e89410, 2014. 


\section{MR Spectroscopy}

Proton MR spectroscopy allows the evaluation of selected volumes of interest regarding the relative or absolute amount of a variable number of metabolites depending on the strength of the magnetic field and on the sequence utilized $[25,26]$. These includeN-acetyl aspartate (NAA), which is an indicator of neuronal viability and integrity [27-29]; choline-containing compounds (Cho), which are indicators of membrane metabolism [27,28]; myo-Inositol (mI), which is a marker of glial activation [30], and therefore, of neuronal injury and degeneration [31]; and total creatine (Cr),which reflects the energy metabolism in the brain. The $\mathrm{Cr}$ concentration is assumed to remain stable in the healthy brain tissue with intact brain energy metabolism and it is often used as a reference for comparisons [26].

Despite the small sizes of the CNS structures, the CSF motion and the compact bone delimiting the posterior cranial fossa, all representing technical challenges for MR spectroscopy, proton MR spectra of adequate quality can be acquired in few minutes in most of the brainstem and cerebellum structures with the exception of the medulla [32].

Accordingly, several cross-sectional proton MR studies investigated the pons and dentate-peridentate or vermian cerebella in SCA2 gene carriers and healthy control subjects [19,33-42].

A recent meta-analysis of the proton MR spectroscopy studies in spinocerebellar ataxias [43] reported that SCA2 gene carriers showed the more pronounced abnormal neurochemical profiles in the pons and cerebellum compared to SCA1, SCA3, SCA6; and Friedreich's ataxia with decreased NAA/Cr and $\mathrm{Cho} / \mathrm{Cr}$ (Figure 1) and increased $\mathrm{mI} / \mathrm{Cr}$ ratios. Decreased NAA and total NAA concentrations [19,34,41,42], increased total $\mathrm{Cr}$ concentration [34,36,41,42] and increased $\mathrm{mI}$ concentration $[34,41,42]$ have also been reported in the same structures, as has the presence of lactate in the cerebellum $[33,35]$. Two studies at high field $[41,42]$ reported a decrease of glutamate concentration, a marker of neuronal function, in the pons and cerebellum.

Correlations between the neurochemical abnormality and severity of a clinical deficit [35,38,39,41,42], quality of life [42], CAG repeats [34,39], disease duration [34,42] and age at onset of symptoms [34] were reported.

One study [34] investigated additional brain structures in SCA2 gene carriers and healthy controls and reported a decrease of the $\mathrm{NAA} / \mathrm{Cr}$ and increase of the $\mathrm{mI} / \mathrm{Cr}$ ratio in the frontal cortex and basal ganglia.

Importantly, in a recent study, premanifest SCA2 mutation carriers with estimated disease onsets within 10 years had decreased total NAA/mI ratios in the dentate and peridentate region, cerebellar vermis and pons that were in the range of early manifest SCA subjects [42].

In the only available longitudinal proton MR spectroscopy study [40] in five SCA2 patients, no statistically significant differences were observed for NAA/Cr and NAA/Cho ratios between the initial and follow-up examinations performed a mean of 38 months apart.

\section{Functional MRI}

MRI exploiting BOLD contrast is a major tool to non-invasively investigate the brain function in patients with neurological diseases. As in other neurodegenerative diseases [44], clinical impairment hinders assessment of symptomatic SCA2 gene carriers with fMRI during execution of tasks [45], and justifies that resting state fMRI has been the preferred method to investigate brain physiopathology in SCA2 using a variety of analytical approaches [46-49].

In symptomatic SCA2, subjects presenting with ataxia were reported to have decreased connectivity within the cerebellum and between the cerebellum and frontal-parietal cortices [47,48], with a selective decrease of the connectivity of the anterior regions of the cerebellum with the somatosensory cortex and of the posterior regions of the cerebellum with cortical cerebral regions related to cognition and emotion [49] (Figure 6). An increased connectivity of the cerebellum with parietal, frontal and temporal areas was also reported in SCA2 patients in one study [48]. 
A RIGHT LATERAL VIEW

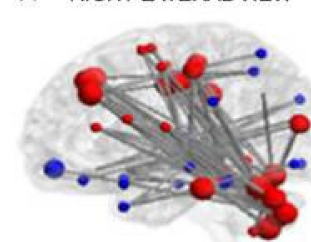

B
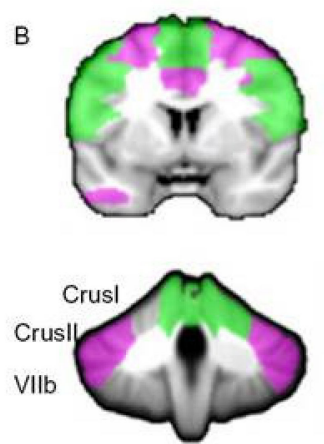
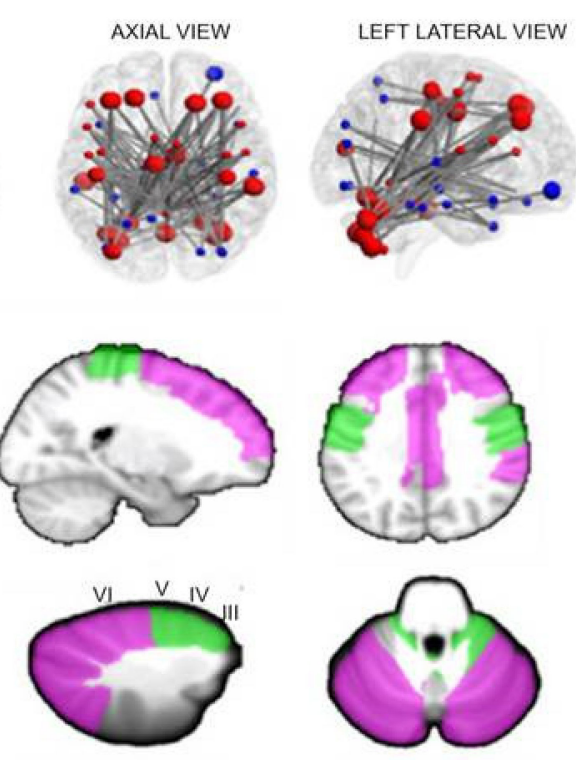

Figure 6. (A,B). Panel A shows the network of significantly decreased functional connectivity in 9 SCA2 patients compared to 33 healthy controls as assessed by network-based statistics analysis. The regions of the cerebello-cortical (red) and cortico-cortical (blue) modules are shown in different colors. Bigger nodes correspond to cerebellar and cortical regions relevant to cognition and emotion; smaller nodes correspond to cerebellar and cortical regions relevant to motor control. Panel B shows the anatomical representations of cognitive (violet) and motor (green) nodes in the cerebellum and cerebral cortex showing underconnectivity between each other. Reproduced from Olivito G, Cercignani M, Lupo M, Iacobacci C, Clausi S, Romano S, Masciullo M, Molinari M, Bozzali M, Leggio M:. Neural substrates of motor and cognitive dysfunctions in SCA2 patients: A network-based statistics analysis. NeuroImage Clin 14:719-725, 2017.

In SCA2 patients presenting with parkinsonism, Wu et al. [46] observed decreased connectivity within the basal ganglia-thalamus-cortical motor loop, and cortico-cortical motor, cortico-cerebellar and cortico-brainstem circuits compared to healthy controls, which were normalized after levodopa treatment. Notably, in pre-symptomatic SCA2 gene carriers of the same families, the connectivity within the basal ganglia-thalamus-cortical motor loop was decreased, but the connectivity of the remainder circuits was increased compared to controls.

One study reported significant correlations between clinical scores and the abnormal functional connectivity strength [48].

No longitudinal study of fMRI in SCA2 gene carriers has been published so far.

\section{Nuclear Medicine}

Positron Emission Tomography (PET) and Single Photon Emission Computed Tomography (SPECT) using different radiotracers enable a multi-domain functional evaluation of the brain and cerebellum that, in comparison to fMRI, has the main drawback of requiring radiation exposures [50,51].

\subsection{Glucose Metabolism}

All the small size studies that used PET and ${ }^{18} \mathrm{~F}$-fluorodeoxyglucose demonstrated severely decreased metabolism in the cerebellar cortex, with preferential involvement of the anterior lobe, the dentate nucleus and brainstem in symptomatic SCA2 gene carriers [52-54] (Figure 7); that was comparatively more pronounced than in SCA3 and SCA6 patients in one study (53). Decreased glucose uptake was observed also in the parahippocampal, frontal and parietal cortices [52,53]. Pre-symptomatic carriers of SCA2 mutation already show hypometabolism in the pons and cerebellum [55]. 

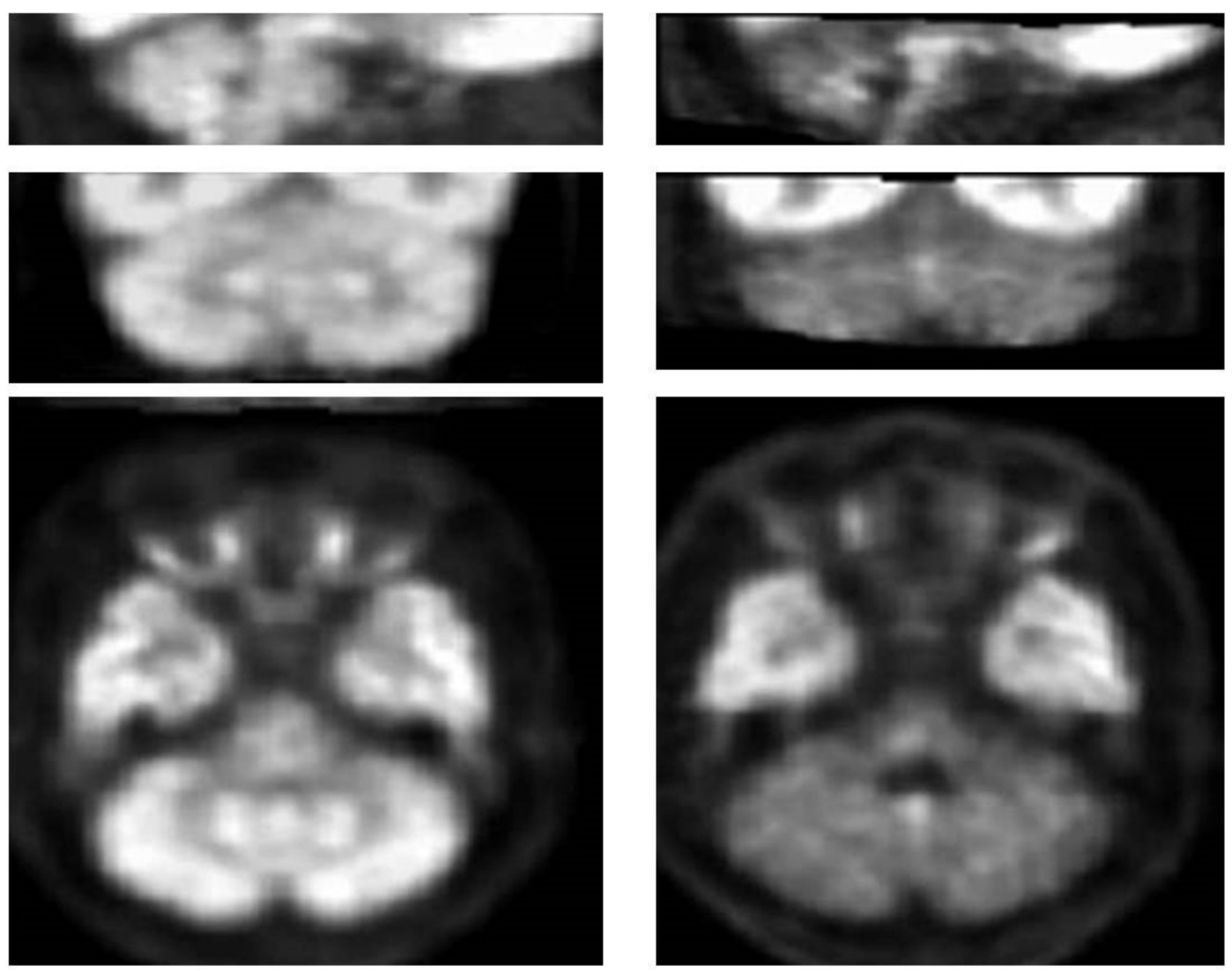

Normal controls

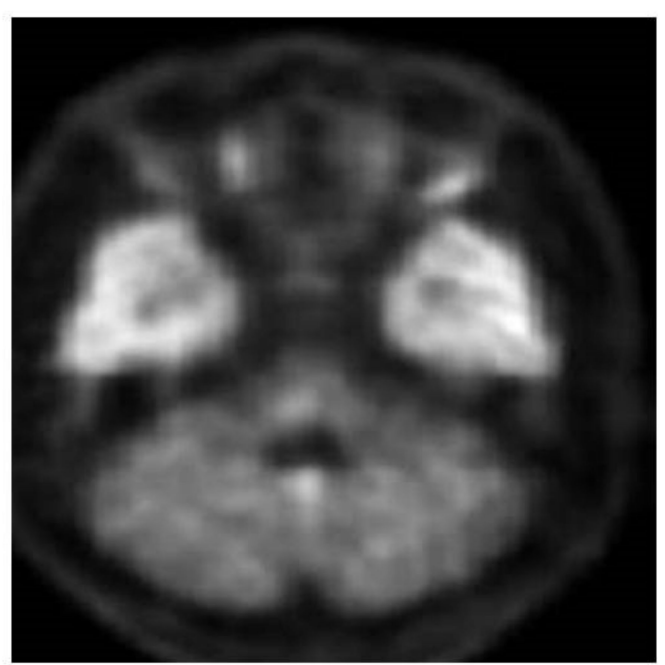

SCA2 patients

Figure 7. 18F-fluorodeoxyglucose positron emission tomography in SCA2.Representative sagittal (top), coronal (mid) and axial (bottom) images of spatially normalized ratios of cerebellar to cerebral 18F-fluorodeoxyglucose uptake using study-specific templates in 89 normal controls (left panels) and 9 patients with SCA2 (right panels) show diffusely decreased hypometabolism in the cerebellar cortex and dentate nuclei (mid and bottom images). Note in the SCA2 patients, the decreased tracer uptake in the basis pontis and medulla oblongata as well (top and bottom images). Modified from Oh M, Kim JS, Oh JS, Lee CS, Chung SJ: Different subregional metabolism patterns in patients with cerebellar ataxia by 18F-fluorodeoxyglucose positron emission tomography. PLoS One 12: e0173275, 2017.

The small sample sizes hindered clinical correlation of this metabolic abnormality in the available studies.

\subsection{Nigrostriatal System}

Almost symmetric nigrostriatal dysfunction secondary to substantia nigra degeneration with decreased striatal uptake of specific tracers is an established feature of SCA2 in symptomatic subjects presenting with cerebellar syndrome or parkinsonism. It has been documented using SPECT and dopamine active transporter (DAT) tracers [56-59] and using PET and both 6-[ $\left.{ }^{18} \mathrm{~F}\right]$ fluoro-L-dopa and positron emitting DAT tracers [52,60-62] (Figure 8). It has also been reported in pre-symptomatic subjects [59]. A voxel-wise analysis revealed that decreased DAT tracer uptake can also be appreciated in the midbrain and pons in SCA2 patients [63]. In line with the responsiveness to levodopa treatment in SCA2 patients with clinical evidence of parkinsonism, striatal D2 receptors are not affected [61,62]. The intriguing coexistence of severe nigrostriatal dysfunction on NM and lack of overt clinical signs of parkinsonism in the majority of SCA2 patients has been explained in a combined NM and neuropathological study by the demonstration of a severe neurodegeneration in the subthalamic nuclei, which, as is observed in clinical cases of amelioration of extrapyramidal sings by stereotactic lesion or 
deep brain stimulation of these nuclei in idiopathic Parkinson's disease, would counteract the effects of severe degeneration of the substantia nigra [62].

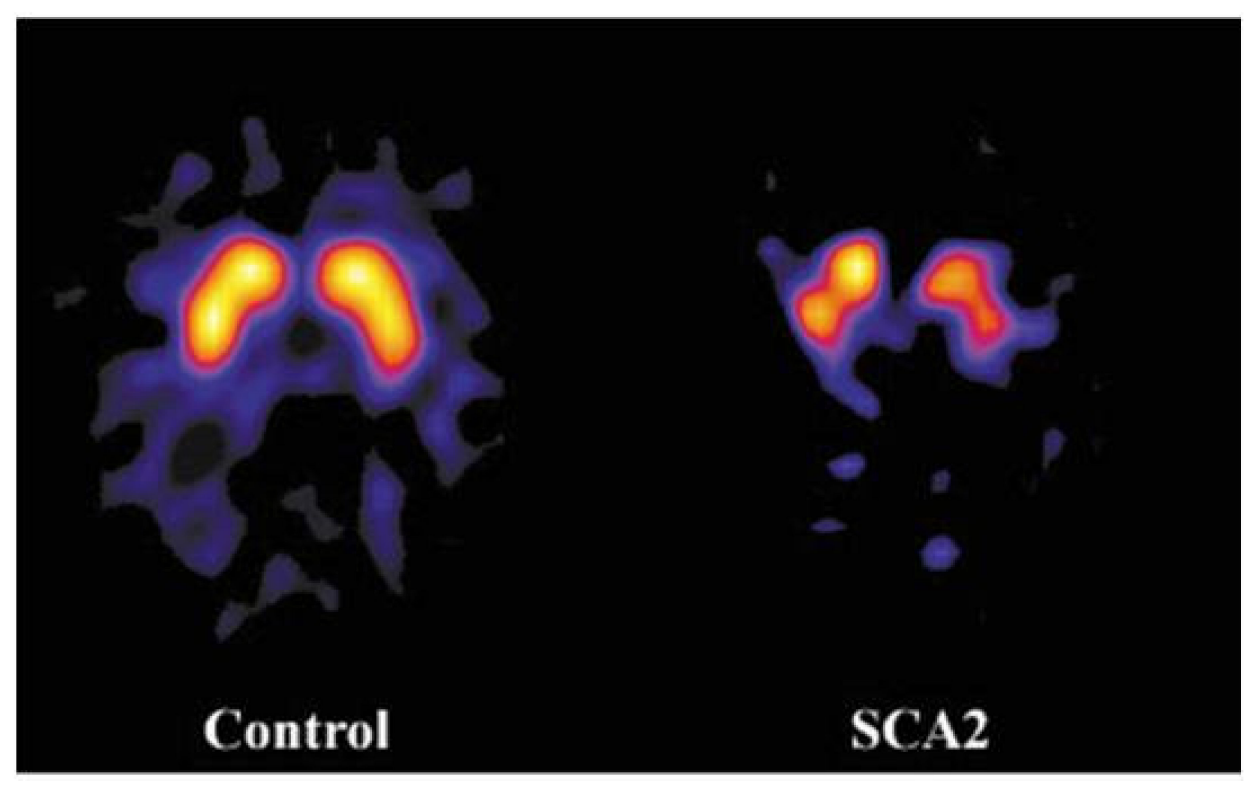

Figure 8. Axial [123I]FP-CIT single photon emission computed tomography scans at the level of the basal ganglia show marked and uniform reduction of the dopamine active transporter (DAT)tracer uptake in a symptomatic SCA2 gene carrier without parkinsonism (right) compared to a control subject (left).Modified and reproduced with permission from Varrone A, Salvatore E, De Michele G, Barone P, Sansone V, Pellecchia MT, Castaldo I, Coppola G, Brunetti A, Salvatore M, et al.: Reduced striatal [123 I]FP-CIT binding in SCA2 patients without parkinsonism. Ann Neurol 55: 426-430, 2004.

Longitudinal NM studies are not available in SCA2.

\section{Limitations and Perspectives}

Rarity of SCA2 justifies the small number of SCA2 gene carriers recruited in single center neuroimaging studies, and, along with heterogeneity of methods, may explain some degree of variability of the results obtained so far. Two solutions have been proposed to overcome this limitation.

1. Meta-analyses of different single studies, such as those recently published by Han et al. [14] for voxel-based morphometry studies and by Krahe et al. [43] for proton MR spectroscopy studies.

2. Data pooling with centralized analyses or re-analyses, as in the European Integrated Project on Spinocerebellar Ataxias (EUROSCA) (www.eurosca.org), the study of individuals at risk for SCA1, SCA2, SCA3 and SCA6 (RISCA) [15] and the ENIGMA project (http://enigma.ini.usc.edu/ ongoing/enigma-ataxia).

Neuroimaging techniques have been advocated as surrogate markers [6] for the next coming clinical trials of spinocerebellar ataxias driven by advancements in genetic and molecular understanding as well as in pharmacological [64] and neurophysiological treatments $[65,66]$. In particular, due to the relative insensitivity of clinical scales [67] and the possibility of a "ceiling effect" hindering reversal of severe clinical deficits in patients with advanced disease, inclusion of neuroimaging data as surrogate markers would theoretically allow for conducting proof-of-concept and efficacy studies with smaller numbers of patients [6].

Although until now the use of neuroimaging techniques as surrogate markers in patients with chronic ataxias has been limited to few exploratory, observational, single center studies that recruited few patients [7], some specific considerations on SCA2 are in order. 
Converging data from different neuroimaging techniques $[12,43,53]$ indicate that the severity of neurodegeneration in SCA2 featuring an OPCA pattern exceeds levels of severity in other SCAs. This implies that SCA2 gene carriers may deserve priority as targets for proof-of concept therapeutic studies in humans with spinocerebellar ataxias.

Structural (volumes) and microstructural data have already demonstrated their capability to track progression of neurodegeneration in SCA2 [13,23,24] and this candidate's T1-weighted MR images and DTI as potential surrogate biomarkers. However, the scarce elastic properties of volumetry makes it not very attractive for such a purpose. In fact, only a modification of the slope of volume loss over time can conceivably be expected in responders to therapy compared to untreated control patients. Hence greater expectations as surrogate neuroimaging biomarkers are being turned to DTI, and especially, proton MR spectroscopy, resting state fMRI and NM [7,41,42]. However, the sensitivity and robustness of each of these neuroimaging methods in this context have not yet proven. The search for the best surrogate marker for futureclinical trials in SCAs represents the current challenge for the neuroimaging community.

\section{Conclusions}

Neuroimaging techniques explore brain structure and microstructure with morphometry and diffusion MRI, the neurochemical profile with proton MR spectroscopy, the functional connectivity with resting state fMRI; and metabolism and nigrostriatal function with PET and SPECT. These quantitative features are valuable physiopathological biomarkers in SCA2 symptomatic and asymptomatic gene carriers. Morphometry and diffusion MRI allow tracking neurodegeneration. Although proton MR spectroscopy, resting state fMRI and PET and SPECT are expected to be more sensitive biomarkers of disease progression, this has not been proven so far. Overcoming the small size typical of single center neuroimaging studies for a rare disease, SCA2 studies are undergoing data pooling in specific initiatives. A selection of the best surrogate biomarker represents the current challenge of the neuroimaging community in view of coming therapies.

Funding: This research received no external funding.

Conflicts of Interest: The authors declare no conflict of interest.

\section{References}

1. Stoyas, C.A.; La Spada, A.R. The CAG-polyglutamine repeat diseases: A clinical, molecular, genetic, and pathophysiologic nosology. Handb. Clin. Neurol. 2018, 147, 143-170. [PubMed]

2. Lastres-Becker, I.; Rub, U.; Auburg, G. Spinocerebellar Ataxia 2 (SCA2). Cerebellum 2008, 7, 115-124. [CrossRef] [PubMed]

3. Ishida, C.; Komai, K.; Yonezawa, K.; Sakajiri, K.; Nitta, E.; Kawashima, A.; Yamada, M. An autopsy case of an aged patient with spinocerebellar ataxia type 2. Neuropathology 2011, 31, 510-518. [CrossRef] [PubMed]

4. Rub, U.; Schols, L.; Paulson, H.; Auburger, G.; Kermer, P.; Jen, J.C.; Seidel, K.; Korf, H.W.; Deller, T. Clinical features, neurogenetics and neuropathology of the polyglutamine spinocerebellar ataxias type 1, 2, 3, 6 and 7 . Progr. Neurobiol. 2013, 104, 38-66. [CrossRef] [PubMed]

5. Koeppen, A. The neuropathology of the adult cerebellum. Hand. Clin. Neurol. 2018, 154, 129-149.

6. Baldaçara, L.; Currie, S.; Hadjivassiliou, M.; Hoggard, N.; Jack, A.; Jackowski, A.P.; Mascalchi, M.; Parazzini, C.; Reetz, J.; Righini, A.; et al. Consensus Paper: Radiological biomarkers of cerebellar diseases. Cerebellum 2015, 14, 175-196. [CrossRef]

7. Mascalchi, M.; Vella, A. Neuroimaging applications in chronic ataxias. Int. Rev. Neurobiol. 2018, 143, 109-162.

8. Burk, K.; Abele, M.; Fetter, M.; Dichgans, J.; Skalej, M.; Laccone, F.; Didierjean, O.; Brice, A.A.; Klockgether, T. Autosomal dominant cerebellar ataxia type I. Clinical features and MRI in families with SCA1, SCA2 andSCA3. Brain 1996, 119, 1497-1505. [CrossRef]

9. Mandelli, M.L.; De Simone, T.; Minati, L.; Bruzzone, M.G.; Mariotti, C.; Fancellu, R.; Savoiardo, M.; Grisoli, M. Diffusion tensor imaging of spinocerebellar ataxias types 1 and 2. AJNR Am. J. Neuroradiol. 2007, 28, 1996-2000. [CrossRef] 
10. Lee, Y.C.; Liu, C.S.; Wu, H.M.; Wang, P.S.; Chang, M.H.; Soong, B.W. The 'hot cross bun' sign in the patients with spinocerebellar ataxia. Eur. J. Neurol. 2009, 16, 513-516. [CrossRef]

11. Mascalchi, M.; Vella, A. Magnetic resonance and nuclear medicine imaging in ataxias. Handb. Clin. Neurol. 2012, 103, 85-110. [PubMed]

12. Klockgether, T.; Skalej, M.; Wedekind, D.; Luft, R.; Welte, D.; Schulz, J.B.; Abele, M.; Burk, K.; Laccone, F.; Brice, A.; et al. Autosomal Dominant Ataxia Type I. MRI-based volumetry of the posterior fossa structures and basal ganglia in spinocerebellar ataxias type 1, 2 and 3. Brain 1998, 121, 1687-1693. [CrossRef]

13. Mascalchi, M.; Diciotti, S.; Giannelli, M.; Ginestroni, A.; Soricelli, A.; Nicolai, E.; Aiello, M.; Tessa, C.; Galli, L.; Dotti, M.T.; et al. Progression of brain atrophy in SCA2. A longitudinal TBM study. PLoS ONE 2014, 9, e89410. [CrossRef] [PubMed]

14. Han, Q.; Yang, J.; Xiong, H.; Shang, H. Voxel-based meta-analysis of gray and white matter volume abnormalities in spinocerebellar ataxia type 2. Brain Behav. 2018, 8, e01099. [CrossRef] [PubMed]

15. Jacobi, H.; Reetz, K.; du Montcel, S.T.; Bauer, P.; Mariotti, C.; Nanetti, L.; Rakowicz, M.; Sulek, A.; Durr, A.; Perrine, C.; et al. Biological and clinical characteristics of individuals at risk for spinocerebellar ataxia types 1, 2, 3, and 6 in the longitudinal RISCA study: Analysis of baseline data. Lancet Neurol. 2013, 12, 650-658. [CrossRef]

16. Reetz, K.; Rodríguez-Labrada, R.; Dogan, I.; Mirzazade, S.; Romanzetti, S.; Schulz, J.B.; Cruz-Rivas, E.M.; Alvarez-Cuesta, J.A.; Aguilera Rodríguez, R.; Gonzalez Zaldivar, Y. Brain atrophy measures in preclinical and manifest spinocerebellar ataxia type 2. Ann. Clin. Transl. Neurol. 2018, 5, 128-137. [CrossRef]

17. Della Nave, R.; Ginestroni, A.; Tessa, C.; Salvatore, E.; De Grandis, D.; Plasmati, R.; Salvi, F.; De Michele, G.; Dotti, M.T.; Piacentini, S.; et al. Brain white matter damage in SCA1 and SCA2. An in vivo study using voxel-based morphometry, histogram analysis of mean diffusivity and tract-based spatial statistics. NeuroImage 2008, 43, 10-19. [CrossRef]

18. Marzi, C.; Ciulli, S.; Giannelli, M.; Ginestroni, A.; Tessa, T.; Mascalchi, M.; Diciotti, S. Structural complexity of the cerebellum and cerebral cortex is reduced in spinocerebellar ataxia type 2. J. Neuroimaging 2018, 28, 688-693. [CrossRef]

19. Guerrini, L.; Lolli, F.; Ginestroni, A.; Belli, G.; Della Nave, R.; Tessa, C.; Foresti, S.; Cosottin, M.; Piacentini, S.; Salvi, F.; et al. Brainstem neurodegeneration correlates with clinical dysfunction in SCA1 but not in SCA2. A volumetric, diffusion and quantitative proton spectroscopy MR study. Brain 2004, 127, 1785-1795.

20. Salvatore, E.; Tedeschi, E.; Mollica, C.; Tedeschi, E.; Mollica, C.; Vicidomini, C.; Varrone, A.; Coda, A.R.; Brunetti, A.; Salvatore, M.; et al. Supratentorial and infratentorial damage in spinocerebellar ataxia 2: A diffusion-weighted MRI study. Mov. Disord. 2014, 29, 780-786. [CrossRef]

21. Hernandez-Castillo, C.R.; Galvez, V.; Mercadillo, R.; Diaz, R.; Campos-Romo, A.; Fernandez-Ruiz, J. Extensive white matter alterations and its correlations with ataxia severity in SCA 2 patients. PLOS ONE 2015, 10, e0135449. [CrossRef] [PubMed]

22. Olivito, G.; Lupo, M.; Iacobacci, C.; Clausi, S.; Romano, S.; Masciullo, M.; Cercignani, M.; Bozzali, M.; Leggio, M. Microstructural MRI basis of the cognitive functions in patients with spinocerebellar ataxia type 2. Neuroscience 2017, 366, 44-53. [CrossRef] [PubMed]

23. Adanyeguh, I.M.; Perlbarg, V.; Henry, P.G.; Rinaldi, D.; Petit, E.; Valabregue, R.; Brice, A.; Durr, A.; Mochel, F. Autosomal dominant cerebellar ataxias: Imaging biomarkers with high effect sizes. NeuroImage Clin. 2018, 19, 858-867. [CrossRef] [PubMed]

24. Mascalchi, M.; Marzi, C.; Giannelli, M.; Ciulli, S.; Bianchi, A.; Ginestroni, A.; Tessa, C.; Nicolai, E.; Aiello, M.; Salvatore, E.; et al. Histogram analysis of DTI-derived indices reveals pontocerebellar degeneration and its progression in SCA2. PLoS ONE 2018, 13, e0200258. [CrossRef]

25. Cousins, J.P. Perspective clinical MR Spectroscopy: Fundamentals, current applications, and future potential. AJR Am. J. Roentgenol. 1995, 164, 1337-1347. [CrossRef]

26. Öz, G. Magnetic Resonance Spectroscopy of Degenerative Brain Diseases, 1st ed.; Springer: Basel, Switzerland, 2016.

27. Gill, S.S.; Small, R.K.; Thomas, D.G.T.; Patel, P.; Porteous, R.; Van Bruggen, N.; Gadian, D.G.; Kauppinen, R.A.; Williams, S.R. Brain metabolites as1H NMR markers of neuronal and glial disorders. NMR Biomed. 1989, 2, 196-200. [CrossRef]

28. Miller, B.L. A review of chemical issues in 1H NMR spectroscopy: N-acetyl-1-aspartate, creatine and choline. NMR Biomed. 1991, 4, 47-52. [CrossRef] 
29. Tsai, G.; Coylet, J.T. N-Acetylaspartate in neuropsychiatric disorders. Prog. Neurobiol. 1995, 46, 531-540. [CrossRef]

30. Brand, A.; Richter-Landsberg, C.; Leibfritz, D. Multinuclear NMR studies on the energy metabolism of glial and neuronal cells. Dev. Neurosci. 1993, 15, 289-298. [CrossRef]

31. Duarte, J.M.N.; Lei, H.; Mlynárik, V.; Gruetter, R. The neurochemical profile quantified by in vivo $1 \mathrm{HNMR}$ spectroscopy. Neuroimage 2012, 61, 342-362. [CrossRef]

32. Mascalchi, M.; Brugnoli, R.; Guerrini, L.; Belli, G.; Nistri, M.; Politi, L.S.; Gavazzi, C.; Lolli, F.; Argenti, G.; Villari, N. Single voxel long TE MR spectroscopy of the normal brainstem and cerebellum. J. Magn. Reson. Imaging 2002, 16, 532-537. [CrossRef] [PubMed]

33. Boesch, S.M.; Schocke, M.; Bürk, K.; Hollosi, P.; Fornai, F.; Aichner, F.T.; Poewe, W.; Felber, S. Proton magnetic resonance spectroscopic imaging reveals differences in spinocerebellar ataxia types 2 and 6. J. Magn. Reson. Imaging 2001, 13, 553-559. [CrossRef] [PubMed]

34. Viau, M.; Marchand, L.; Bard, C.; Boulanger, Y. 1H magnetic resonance spectroscopy of autosomal ataxias. Brain Res. 2005, 1049, 191-202. [CrossRef] [PubMed]

35. Boesch, S.M.; Wolf, C.; Seppi, K.; Felber, S.; Wenning, G.K.; Schocke, M. Differentiation of SCA2 from MSA-C using proton magnetic resonance spectroscopic imaging. J. Magn. Reson. Imaging 2007, 25, 564-569. [CrossRef] [PubMed]

36. Guerrini, L.; Belli, G.; Mazzoni, L.N.; Ginestroni, A.; Foresti, S.; Diciotti, S.; Della Nave, R.; Mascalchi, M. Impact of CSF contamination on brain metabolites evaluation with ${ }^{1} \mathrm{H}-\mathrm{MR}$ spectroscopy. A single voxel study of the cerebellar vermis in patients with degenerative ataxias. J. Magn. Reson. Imaging 2009, 30, 11-17. [CrossRef]

37. Oz, G.; Iltis, I.; Hutter, D.; Thomas, W.; Bushara, K.O.; Gomez, C.M. Distinct neurochemical profiles of spinocerebellar ataxias 1, 2, 6, and cerebellar multiple system atrophy. Cerebellum 2011, 10, 208-217. [CrossRef]

38. Lirng, J.F.; Wang, P.S.; Chen, H.C.; Soong, B.W.; Guo, W.Y.; Wu, H.M.; Chang, C.Y. Differences between spinocerebellar ataxias and multiple system atrophy-cerebellar type on proton magnetic resonance spectroscopy. PLoS ONE 2012, 7, e47925. [CrossRef]

39. Wang, P.S.; Chen, H.C.; Wu, H.M.; Lirng, J.F.; Wu, Y.T.; Soong, B.W. Association between Proton Magnetic Resonance Spectroscopy measurements and CAG repeat number in patients with Spinocerebellar Ataxias 2, 3, or 6. PLoS ONE 2012, 7, e47479. [CrossRef]

40. Chen, H.C.; Lirng, J.F.; Soong, B.W.; Guo, W.Y.; Wu, H.M.; Chen, C.C.; Chang, C.Y. The merit of proton magnetic resonance spectroscopy in the longitudinal assessment of spinocerebellar ataxias and multiple system atrophy-cerebellar type. Cerebellum Ataxias 2014, 1, 17. [CrossRef]

41. Adanyeguh, I.M.; Henry, P.G.; Nguyen, T.M.; Rinaldi, D.; Jauffret, C.; Valabregue, R.; Emir, U.E.; Deelchand, D.K.; Brice, A.; Eberly, L.E.; et al. In vivo neurometabolic profiling in patients with spinocerebellar ataxia types 1, 2, 3, and 7. Mov. Disord. 2015, 30, 662-670. [CrossRef]

42. Joers, J.M.; Deelchand, D.K.; Lyu, T.; Emir, U.E.; Hutter, D.; Gomez, C.; Bushara, K.O.; Eberly, L.E.; Öz, G. Neurochemical abnormalities in premanifest and early spinocerebellar ataxias. Ann. Neurol. 2018, 83, 816-829. [CrossRef] [PubMed]

43. Krahe, J.; Binkofski, F.; Schulz, J.B.; Reetz, K.; Romanzetti, S. Neurochemical profiles in hereditary ataxias: A meta-analysis of Magnetic Resonance Spectroscopy studies. Neurosci. Biobehav. Rev. 2019, 108, 854-865. [CrossRef] [PubMed]

44. Hohenfeld, C.; Werner, C.J.; Reetz, K. Resting-state connectivity in neurodegenerative disorders: Is there potential for an imaging biomarker? NeuroImage Clin. 2018, 18, 849-870. [CrossRef]

45. Price, C.J.; Crinion, J.; Friston, K.J. Design and analysis of fMRI studies with neurologically impaired patients. J. Magn. Reson. Imaging 2006, 23, 816-826. [CrossRef]

46. Wu, T.; Wang, C.; Wang, J.; Ha llett, M.; Zang, Y.; Chan, P. Preclinical and clinical neural network changes in SCA2 parkinsonism. Parkinsonism Relat. Disord. 2013, 19, 158-164. [CrossRef]

47. Cocozza, S.; Saccà, F.; Cervo, A.; Marsili, A.; Russo, C.V.; Giorgio, S.M.; De Michele, G.; Filla, A.; Brunetti, A.; Quarantelli, M. Modifications of resting state networks in spinocerebellar ataxia type 2. Mov. Disord. 2015, 30, 1382-1390. [CrossRef]

48. Hernandez-Castillo, C.R.; Galvez, V.; Mercadillo, R.E.; Díaz, R.; Yescas, P.; Martinez, L.; Ochoa, A.; Velazquez-Perez, L.; Fernandez-Ruiz, J. Functional connectivity changes related to cognitive and motor performance in spinocerebellar ataxia type 2. Mov. Disord. 2015, 30, 1391-1399. [CrossRef] 
49. Olivito, G.; Cercignani, M.; Lupo, M.; Iacobacci, C.; Clausi, S.; Romano, S.; Masciullo, M.; Molinari, M.; Bozzali, M.; Leggio, M. Neural substrates of motor and cognitive dysfunctions in SCA2 patients: A network-based statistics analysis. NeuroImage Clin. 2017, 14, 719-725. [CrossRef]

50. Mascalchi, M.; Vella, A.; Ceravolo, R. Movement disorders: Role of imaging in diagnosis. J. Magn. Reson. Imaging 2012, 35, 239-256. [CrossRef]

51. Vella, A.; Mascalchi, M. Nuclear medicine of the cerebellum. Handb. Clin. Neurol. 2018, 154, 251-266.

52. Wüllner, U.; Reimold, M.; Abele, M.; Bürk, K.; Minnerop, M.; Dohmen, B.M.; Machulla, H.J.; Bares, R.; Klockgether, T. Dopamine Transporter Positron Emission Tomography in Spinocerebellar Ataxias Type 1, 2 , 3, and 6. Arch. Neurol. 2005, 62, 1280-1285. [CrossRef]

53. Wang, P.S.; Liu, R.S.; Yang, B.H.; Soong, B.W. Regional patterns of cerebral glucose metabolism in spinocerebellar ataxia type 2, 3 and 6: A voxel-based FDG-positron emission tomography analysis. J. Neurol. 2007, 254, 838-845. [CrossRef]

54. Oh, M.; Kim, J.S.; Oh, J.S.; Lee, C.S.; Chung, S.J. Different subregional metabolism patterns in patients with cerebellar ataxia by 18F-fluorodeoxyglucose positron emission tomography. PLoS ONE 2017, 12, e0173275. [CrossRef] [PubMed]

55. Inagaki, A.; Iida, A.; Matsubara, M.; Inagaki, H. Positron emission tomography and magnetic resonance imaging in spinocerebellar ataxia type 2: A study of symptomatic and asymptomatic individuals. Eur. J. Neurol. 2005, 12, 725-728. [CrossRef]

56. Lu, C.S.; Wu Chou, Y.H.; Yen, T.C.; Tsai, C.H.; Chen, R.S.; Chang, H.C. Dopa-responsive parkinsonism phenotype of spinocerebellar ataxia type 2. Mov. Disord. 2002, 17, 1046-1051. [CrossRef] [PubMed]

57. Boesch, S.M.; Donnemiller, E.; Müller, J.; Seppi, K.; Weirich-Schwaiger, H.; Poewe, W.; Wenning, G.K. Abnormalities of dopaminergic neurotransmission in SCA2: A combined 123I-betaCIT and 123I-IBZM SPECT study. Mov. Disord. 2004, 19, 1320-1325. [CrossRef]

58. Varrone, A.; Salvatore, E.; De Michele, G.; Barone, P.; Sansone, V.; Pellecchia, M.T.; Castaldo, I.; Coppola, G.; Brunetti, A.; Salvatore, M.; et al. Reduced striatal [123 I]FP-CIT binding in SCA2 patients without parkinsonism. Ann. Neurol. 2004, 55, 426-430. [CrossRef]

59. Kim, J.M.; Hong, S.; Kim, G.P.; Choi, Y.J.; Kim, Y.K.; Park, S.S.; Kim, S.E.; Jeon, B.S. Importance of low-range CAG expansion and CAA interruption in SCA2 Parkinsonism. Arch. Neurol. 2007, 64, 1510-1518. [CrossRef]

60. Shan, D.E.; Soong, B.W.; Sun, C.M.; Lee, S.J.; Liao, K.K.; Liu, R.S. Spinocerebellar ataxia type 2 presenting as familial levodopa-responsive parkinsonism. Ann. Neurol. 2001, 50, 812-815. [CrossRef]

61. Furtado, S.; Farrer, M.; Tsuboi, Y.; Klimek, M.L.; de la Fuente-Fernández, R.; Hussey, J.; Lockhart, P.; Calne, D.B.; Suchowersky, O.; Stoessl, A.J.; et al. SCA-2 presenting as parkinsonism in an Alberta family: Clinical, genetic, and PET findings. Neurology 2002, 59, 1625-1627. [CrossRef]

62. Schöls, L.; Reimold, M.; Seidel, K.; Globas, C.; Brockmann, K.; Hauser, T.K.; Auburger, G.; Bürk, K.; den Dunnen, W.; Reischl, G.; et al. No parkinsonism in SCA2 and SCA3 despite severe neurodegeneration of the dopaminergic substantia nigra. Brain 2015, 138, 3316-3326. [CrossRef] [PubMed]

63. Scherfler, C.; Boesch, S.M.; Donnemiller, E.; Seppi, K.; Weirich-Schwaiger, H.; Goebel, G.; Virgolini, I.; Wenning, G.K.; Poewe, W. Topography of cerebral monoamine transporter availability in families with SCA2 mutations: A voxel-wise [123I]beta-CIT SPECT analysis. Eur. J. Nucl. Med. Mol. Imaging 2006, 33, 1084-1090. [CrossRef] [PubMed]

64. Ashizawa, T.; Öz, G.; Paulson, H.L. Spinocerebellar ataxias: Prospects and challenges for therapy development. Nat. Rev. Neurol. 2018, 14, 590-605. [CrossRef] [PubMed]

65. Pirker, W.; Back, C.; Gerschlager, W.; Laccone, F.; Alesch, F. Chronic thalamic stimulation in a patient with spinocerebellar ataxia type 2. Mov. Disord. 2003, 18, 222-225. [CrossRef] [PubMed]

66. Pope, P.A.; Miall, R.C. Restoring cognitive functions using non-invasive brain stimulation techniques in patients with cerebellar disorders. Front. Psychiatry 2014, 5, 33. [CrossRef] [PubMed]

67. Schulte, T.; Schols, L. The use of quantitative methods in clinical trials for spinocerebellar ataxia. Arch. Neurol. 2002, 59, 1044-1045.

(C) 2020 by the authors. Licensee MDPI, Basel, Switzerland. This article is an open access article distributed under the terms and conditions of the Creative Commons Attribution (CC BY) license (http://creativecommons.org/licenses/by/4.0/). 